\title{
Study on the Microstructure and Properties of Laser Remelted Ceramic Coatings on Low Carbon Steel Surface
}

\author{
QU Xing-tian ${ }^{\mathrm{a}}$, GUO Xiao-jian ${ }^{\mathrm{b}}$, Wang Xin ${ }^{{ }^{*}}$ and Jiang Xin ${ }^{\mathrm{d}}$ \\ Dept. of Mechanical Manufacturing and Automation, Ji Lin University, Chang Chun 130025, China \\ aquxt@jlu.edu.cn, b18943958767@163.com, ${ }^{\text {'wxin@jlu.edu.cn, }{ }^{d} 78914462 @ q q . c o m}$
}

Keywords: $\mathrm{Al}_{2} \mathrm{O}_{3}-13 \% \mathrm{TiO}_{2}$; Plasma spraying ; Laser remelting ; Coating properties

Abstract. The plasma spraying $\mathrm{Al}_{2} \mathrm{O}_{3}-13 \% \mathrm{TiO}_{2}$ (hereinafter referred to as AT-13) ceramic coating on Q235B steel surface was dealt with laser remelting technique, then change of the microstructure and properties of the laser remelting AT-13 coating was studied. The experiment results show that the microstructure of laser remelted ceramic coatings is very dense, and no porosity appears. The main composition of laser remelted ceramic coatings is $\alpha-\mathrm{Al}_{2} \mathrm{O}_{3}$ and a small amount of $\mathrm{TiO}_{2}$ and $\mathrm{TiAl}_{2} \mathrm{O}_{5}$. Micro hardness of AT-13 plasma spraying coating was measured with micro sclerometer and the maximum value of micro hardness $\mathrm{HV}_{0.2}$ was 998 , while the maximum value of micro hardness $\mathrm{HV}_{0.2}$ of laser remelting coatings was 1710; Bonding strength of AT-13 plasma spraying layer was measured through the tensile test and the average value is $24.36 \mathrm{MPa}$, while bonding strength of laser remelting coating was more than $68.8 \mathrm{Mpa}$. The wear resistance of laser remelting coatings is higher than that of AT-13 plasma spraying layer through the pin dish particle attrition test.

\section{Introduction}

Along with the development of the top science and the modern industry, various industry departments increasingly require that mechanical equipment can keep a long-term stable operation in various circumstances, and put forward higher requirements on performance of material. The price of high performance material is expensive, led to that the high performance material cannot be to use in the wide range of mass production. In view of the common material performance which is difficult to meet the requirements of today's processing, The research and development of the treatment technology of the material surface has an important technical and economic significance[1,2].

Ceramic material has wear-resisting, corrosion resistant, heat resistant and high temperature oxidation resistance and other excellent performance which other conventional materials do not have, but its brittleness, sensitive to stress and crack, resistant to fatigue performance is poor and hard to process, and making its application is limited[3-5]. Surface engineering technology can organically combine the characteristics of the matrix metal and ceramic coating on the surface, and fully exploit the comprehensive advantages of two kinds of materials, to obtain the ideal performance of composite material structure[6].

The plasma spraying techniques has been widely used in industrial production as a kind of surface engineering technology because of Process simple, low cost, wide material application . But coating forming process inevitably exists some porosity and cavity between particles and particles, and accompanied by oxide inclusions, these factors which may make coating instability in process are easy to cause failure due to fall off. Laser cladding, which is one method of the important material surface melting technology, can effectively improve the performance of ceramic coating. It used the feature that high energy density laser beam can fastly melt substrate surface and the alloy with the different components to form the alloy which has a totally different composition and performance With the substrate on the surface of the matrix. It can use the high performance surface coating which is made on the low-cost steel plate to instead of precious metals or alloys. In order to get the coating quality results. In the first place ,spraying on the matrix AT-13 metal ceramic powder by plasma spraying device. Then Coating by laser remelting and using the related testing instrument to test quality of 
various performance parameters of coating after remelting. Finally, getting the coating quality results through the contrast analysis.

\section{The methods of test}

\section{The material of coating}

Q235B steel has been Selected as the substrate material. According to the requirements of the testing matrix material, the substrate material should be designed for rod and plate respectively. The size of the bar is $\Phi 10 \times 30 \mathrm{~mm}$. The size of the plate is $90 \mathrm{~mm} \times 90 \mathrm{~mm} \times 5 \mathrm{~mm} . \quad \mathrm{Al}_{2} \mathrm{O}_{3}-13 \%$ $\mathrm{TiO}_{2}$ (Shorthand for the AT-13) Metal ceramic powder materials is Selected as the material of coating. $\mathrm{Ni}-\mathrm{Al}$ is chosen as the underlying spraying material, which is Provided by the siping GSD Nano-materials company. It can be use to improve the ability of the combination of coating and substrate. Its size is $140 \sim 260 \mathrm{um}$.

\section{The Preparation technology and equipment of coating}

$\mathrm{Ni}-\mathrm{Al}$ layer and the AT-13 ceramic layer is sprayed and pre-made by The plasma spraying equipment GSD-80k. The method of trichloroethylene vapor degreasing and roughening of the surface is adopted to the pretreatment of substrate. It is need to preheat the substrate, and The temperature at $140{ }^{\circ} \mathrm{C}$. The moisture of the surface of the substrate is removed and the temperature gap between spraying droplet and matrix is reduced. The technological parameters of plasma spraying are shown in table 1. Plasma spray coating is processed by laser cladding equipment which is produced by Wuhan ChuTian industrial laser equipment Co. Ltd. The equipment are JHM-1-GY-150E laser processing machine and JL series laser cooling system. The technological parameters of laser remelting are shown in table 2.

Table 1 Technological parameters of plasma spraying

\begin{tabular}{|c|c|c|c|c|c|c|c|c|}
\hline control & Arc & arc & Argon gas & hydrogen & Send powder & powder & nozzle & spray \\
\hline \multirow[t]{2}{*}{ system } & voltage & current & pressure & pressure & gas pressure & feeding rate & type & distance \\
\hline & /V & /A & /Mpa & $/ \mathrm{MPa}$ & $/ \mathrm{MPa}$ & $/ g \cdot \min$ & & $/ \mathrm{mm}$ \\
\hline $\mathrm{Ni}-\mathrm{Al}$ & 44.4 & 500 & 0.65 & 0.35 & 0.3 & 13.0 & G & 100 \\
\hline AT-13 & 75 & 508 & 0.7 & 0.4 & 0.3 & 13.9 & G & 100 \\
\hline
\end{tabular}

Table 2 Technological parameters of laser remelting

\begin{tabular}{ccccc}
\hline matrix material & Coating Material & laser pulse width & ser current & spot diameter \\
\hline Q235B steel & AT-13 & $1 \mathrm{~ms}$ & $105 \mathrm{~A}$ & $0.3 \mathrm{~mm}^{-1}$ \\
\hline
\end{tabular}

\section{The measures of analysis and test}

The morphology and microstructure of the coatings were analyzed and observed by 4XCZ optical microscope and JSM-6301F scanning electron microscope. D/max2500X ray diffraction can be used to analyze the phase structure of the coating. Microhardness method was used to measure the hardness of the coating. The test equipment is made of 71 type micro hardness tester, and the load is $25 \mathrm{~g}$. In the CSS-44100 electronic universal testing machine, the test was carried out by the loading rate of $6 \mathrm{~mm} / \mathrm{min}-1$. Fig. 1 Schematic diagram of tensile test. E7 epoxy resin adhesive is used to bond the sample A with coating to the sample B with no coating, To remove Spilled the adhesive in order to avoid the "bypass effect" and the impact of test accuracy; The wear resistance of the coating was tested on the ML-100 pin and disc type abrasive wear testing machine. Fig. 2 Schematic diagram of pin - disc abrasive wear test, SiC abrasive sandpaper is arranged on the Disc. Specimen is a pin type. load are 
taken $3 \mathrm{~N}, 5 \mathrm{~N}, 7 \mathrm{~N}$. the disc rotates is $60 \mathrm{R} / \mathrm{min}$. sample has a linear motion along radial direction of the disk, sample radial feed quantity is $3 \mathrm{~mm} / \mathrm{s}$. The weightlessness of the samples was measured by TB328B type electronic Balance( accuracy 0.0001g), And the wear resistance of the coating was evaluated.

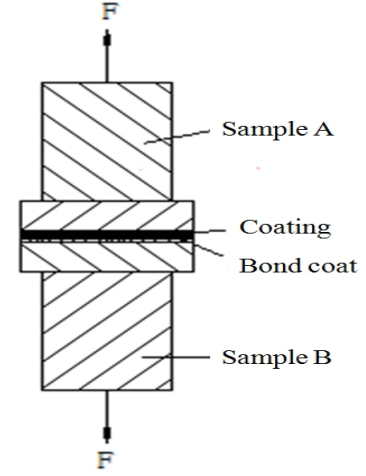

Fig.1 Test schemes of bond strength

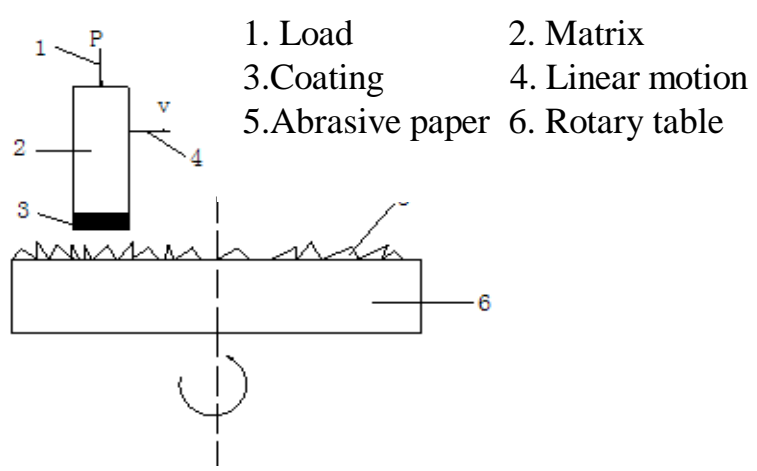

Fig.2 Test schemes of pin disc abrasive wear

\section{Test results and discussion}

\section{metallographic examination of coating structure}

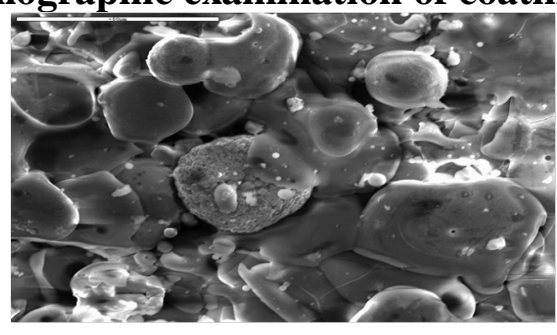

Fig.3 SEM photos of plasma spraying coating

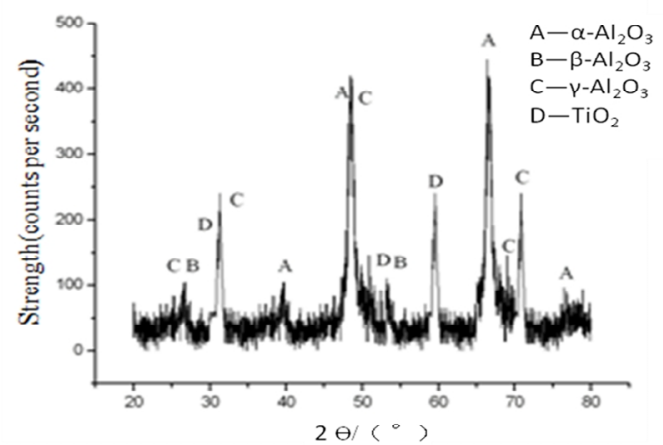

Fig.5 X-ray diffractogram of AT-13 plasma spraying coating

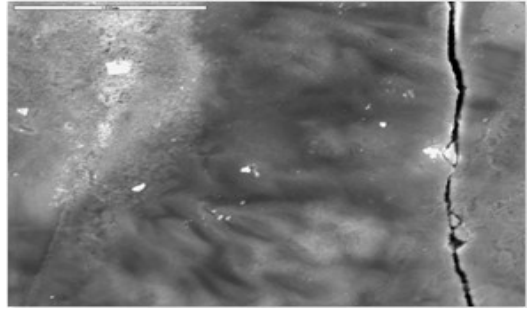

Fig.4 SEM photos of laser remelting coating

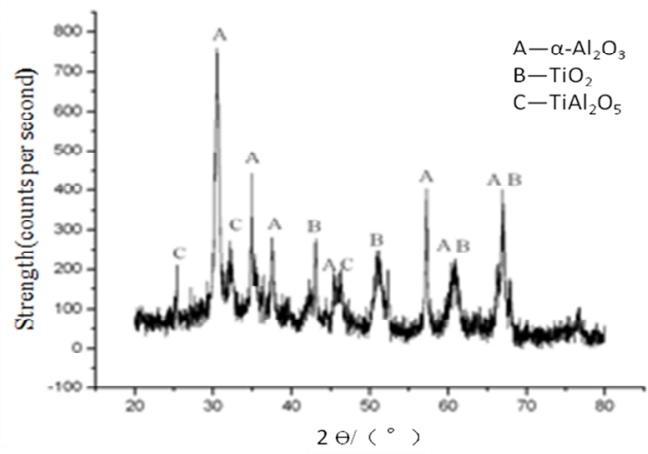

Fig.6 X-ray diffractogram of AT-13 laser remelting coating

From Figure 3, it can be seen that the AT-13 plasma sprayed coating has coating porosity and flat shaped particles, and there are many small particles in the middle of the coating. This is coating impurities. In Figure 4, there are no flat particles, and there is no pore between the particles and the particles. The microstructure of the coating is very smooth, and the coating is composed of columnar crystal and other crystalline grains. The porosity of the coating is completely disappeared. The coating is very compact. There are obvious cracks in the picture for the reason that the laser temperature is high , and the coating will rapidly condense after the melt. With the reducing of temperature and the shrink of coating, there is no liquid metal added to the cracks and the cracks are formed. It can improve the laser remelting process to achieve the full densification of the coating.

Figure 5 is an AT-13-X-ray diffraction pattern of plasma sprayed coatings. From the graph, we can see that $\alpha-\mathrm{Al}_{2} \mathrm{O}_{3}$ is the main part, the ratio of $\gamma-\mathrm{Al}_{2} \mathrm{O}_{3}$ is more than that of $\beta-\mathrm{Al}_{2} \mathrm{O}_{3}$. Figure 6 is a AT-13-X-ray diffraction pattern of laser remelting coating. Comparison of the AT-13 - X - ray diffraction pattern of plasma sprayed coating and it can be found that the phase of the coating has 
changed after laser remelting. All of the $\beta-\mathrm{Al}_{2} \mathrm{O}_{3}$ and $\gamma-\mathrm{Al}_{2} \mathrm{O}_{3}$ in the plasma spray layer are converted to $\alpha-\mathrm{Al}_{2} \mathrm{O}_{3}, \mathrm{Al}_{2} \mathrm{O}_{3}$ reacts with $\mathrm{TiO}_{2}$ to generate $\mathrm{TiAl}_{2} \mathrm{O}_{5}$, but the proportion of $\mathrm{TiAl}_{2} \mathrm{O}_{5}$ is not high, and $\alpha-\mathrm{Al}_{2} \mathrm{O}_{3}$ is the main component of the layer. With the change of the phase, the laser remelting coating also changes in the performance, which mainly reflects the physical and chemical properties of the $\alpha-\mathrm{Al}_{2} \mathrm{O}_{3}$ material.

\section{Hardness test of coating}

Five samples of plasma spraying and laser remelting were selected, and five points were selected on the coating. The data for each point of the curve is the average hardness of each point. The results of the measurement are shown in Figure 7:

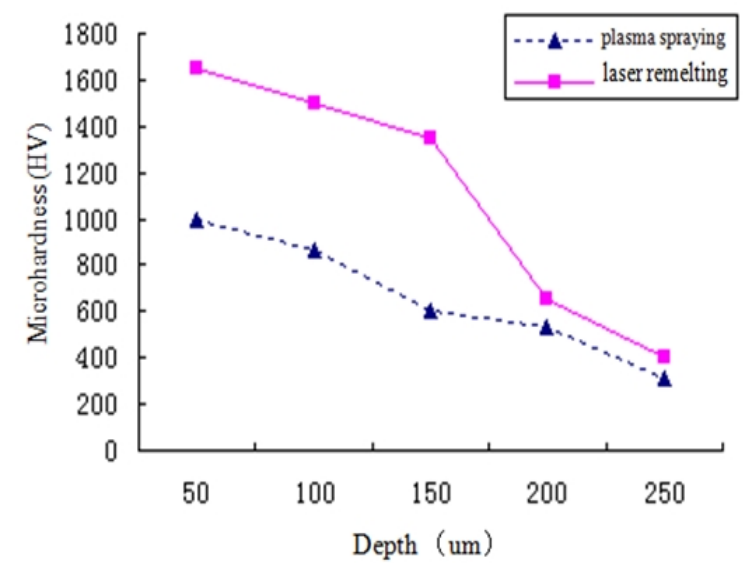

Fig.7 Microhardness of plasma spraying and laser remelting coatings
From Figure 7, it can be seen that the maximum microhardness $\mathrm{HV}_{0.2}$ of the AT-13 plasma sprayed coating is about 998, and the maximum value of the laser remelting coating is about 1710. Compared with the plasma coating, the hardness of the laser remelting layer is obviously improved. The main reasons are: first, the grain has changed, and the uneven layer structure of the coating is almost completely eliminated. The microstructure of the coating is very fine and uniform; Secondly, the porosity of the plasma sprayed layer is high, After the laser remelting, the hole of layer and the defects are greatly reduced, and the density has been greatly improved; Third, due to the rapid melting, the solid solubility of Al based solid solution increases, solid solution strengthens.

It can be seen that the hardness curve of laser remelting coating can be divided into three gradients, which are mainly high hardness, decreased hardness and low hardness zone, which are corresponding to the coating alloy zone、 heat affected zone and the matrix. As a result of the laser remelting coating, the coating gap is greatly reduced, almost fully dense. $\mathrm{Al}_{2} \mathrm{O}_{3}$ has a phase transition in the process of laser remelting. $\gamma-\mathrm{Al}_{2} \mathrm{O}_{3}$ and $\beta-\mathrm{Al}_{2} \mathrm{O}_{3}$ completely disappeared, all converted to $\alpha-\mathrm{Al}_{2} \mathrm{O}_{3}$, and the formation of aluminum titanium compound, which makes the hardness of the coating increased significantly. $\mathrm{Al}_{2} \mathrm{O}_{3}$ is the main component in the alloy, so the hardness of the alloy is high. In the heat affected zone, the proportion of the material composition of the region was changed due to the dilution effect of the laser. The composition of $\mathrm{Ni}$ based compounds and matrix Q235 increased, the proportion of $\mathrm{Al}_{2} \mathrm{O}_{3}$ decreased, the hardness of the region decreased significantly. In the base area, the material of the coating seldom invades. The hardness tends to be flat, and it is close to the hardness of the matrix.

\section{To test the bonding strength of coating and substrate}

In the experiment, both the samples of plasma spraying and laser remelting were five pairs, the measurement data are shown in table 3 and table 4:

Table 3 Tensile testing data of plasma spraying coating

\begin{tabular}{lcccccc}
\hline & $\mathrm{N} 1-1$ & $\mathrm{~N} 2-2$ & $\mathrm{~N} 3-3$ & $\mathrm{~N} 4-4$ & $\mathrm{~N} 5-5$ & average \\
\hline $\begin{array}{l}\text { Rupture maximum load } \\
\text { /KN }\end{array}$ & 7.653 & 7.546 & 7.725 & 7.664 & 7.708 & 7.659 \\
Bonding strength /Mpa & 24.3 & 24.0 & 24.6 & 24.4 & 24.5 & 24.36 \\
\hline
\end{tabular}


Table 4 Tensile testing data of Laser remelting coating

\begin{tabular}{llcccccc}
\hline & & $\mathrm{N} 1-1$ & $\mathrm{~N} 2-2$ & $\mathrm{~N} 3-3$ & $\mathrm{~N} 4-4$ & N5-5 & average \\
\hline Laser remelting & Rupture & 20.9 & 21.2 & 20.5 & 21.6 & 21.0 & 21.04 \\
$\begin{array}{l}\text { maximum load } / \mathrm{KN} \\
\text { Laser remelting }\end{array}$ & bonding & 66.6 & 67.5 & 65.3 & 68.8 & 66.9 & 67.02 \\
strength $/ \mathrm{Mpa}$ & & & & & & & \\
\hline
\end{tabular}

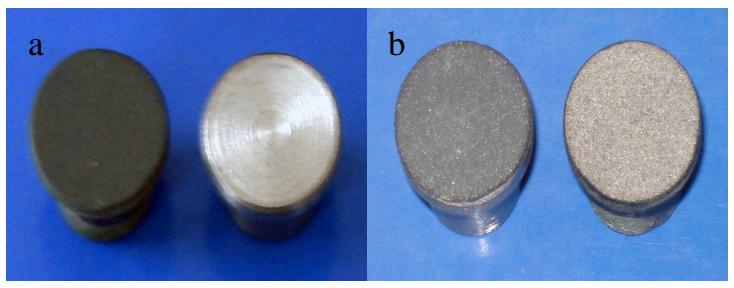

Fig.8 Fracture mode of plasma spraying test sample

Observing section, as shown in Figure 8. Among them, figure $\mathrm{A}$ is the morphology of the specimens before test. Figure B is the morphology of the specimens after tensile test. It is found that the fracture of the specimens which are coated with plasma is the fracture of coating and matrix. Table 3 shows that the experimental data is the bonding strength of the coating and the substrate. Observing section, as shown in Figure 9. Among them, figure A is the morphology of the specimens before test. Figure B is the morphology of the specimens after tensile test. It is found that the cross section of the laser remelting coating is quite different from that of the plasma sprayed coating. The fracture mode of the laser remelting coating is the fracture of the adhesive and the laser remelting layer. The laser remelting layer and the substrate are not destroyed, so the measured data is not the bonding strength of the laser remelting coating and the substrate, but the bond strength of the adhesive. But by the observation of the failure mode of the coating, it can be seen that the bonding strength of the coating and substrate after laser remelting treatment is far greater than that of the plasma sprayed coating.

There are two reasons for the improvement of the adhesion of the coating and the substrate by laser remelting. One is that the combination of the coating and the substrate has changed from mechanical to metallurgical combination. A excessive layer is formed between the coating and substrate after laser remelting. In the excessive layer, there are the coating material component and the matrix component, It has good material temperature and good wetting property. In the crystallization process, its material has good spreadability, long cooling process and good bonding properties between grain and grain. Which makes the coating and substrate have good binding force and high bonding strength. The second reason is that the structure of the coating is refined grain. After laser remelting, the structure of the original sheet layer is eliminate, then the equiaxed grains and the columnar crystals are formed. The particles are fine and uniform, and the inclusion and stomatas are reduced. The coating is almost fully dense, and the coating is more fully integrated with the substrate and the internal coating. The coating and the substrate and the internal coating are more cohesive.

\section{test analysis of wear performance}

From Figure 10, we can draw the following three points. First, the wear resistance of the AT-13 coating after laser remelting is much higher than that of Q235 steel and AT-13 plasma coating. The wear resistance of the coating is 10 times than that of Q235 steel matrix after laser remelting in the $800 \# \mathrm{SiC}$ sandpaper, and also reaches 5 times compared with the plasma coating. Second, the abrasive of different granularity has different effects on the wear performance of the coating, The bigger the particle size is, the more serious the wear of the coating is. Comparing with the wear rate of Q235 on 
the $800 \# \mathrm{SiC}$ sand, the wear rates of Q235 on the $240 \# \mathrm{SiC}$ sand increases by nearly $40 \%$. The wear of the coating also increases after laser remelting, but the increase amplitude is low.

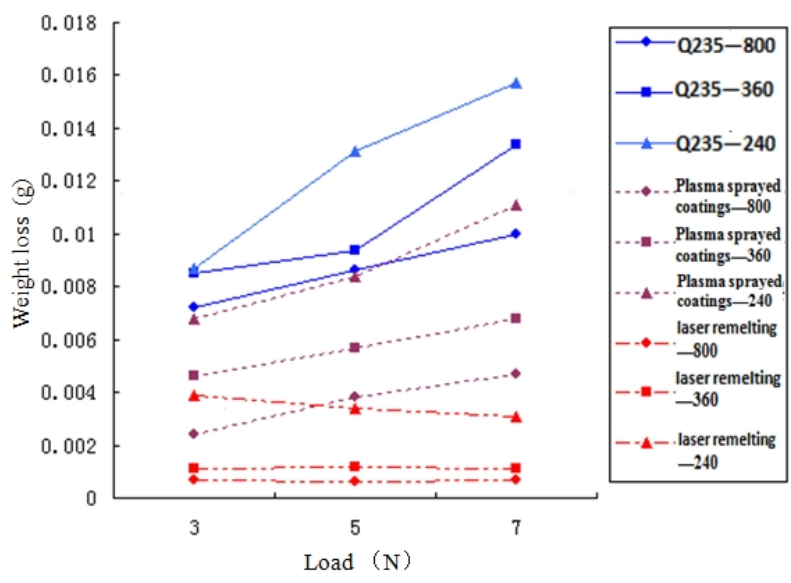

Fig.10 Comparison diagrame wear test

Analysis of experimental results: After laser remelting, the grain size of the coating is fine and uniform, and the equiaxed grain of high hardness is generated. The material of coating has a transformation, and the $\gamma-\mathrm{Al}_{2} \mathrm{O}_{3}$ and $\beta-\mathrm{Al}_{2} \mathrm{O}_{3}$ are all converted to $\alpha-\mathrm{Al}_{2} \mathrm{O}_{3}$, which greatly increases the hardness of the coating. The combination of coating and substrate is changed from mechanical to metallurgical bonding. Densification of coating and the combination of grain and grain in the coating are improved, and the bonding performance is enhanced. Hardness and bonding strength are the two most important factors affecting the wear resistance. After a substantial improvement in the hardness and strength of the bond, the wear resistance of the coating has been greatly improved.

\section{Summary}

(1) After laser remelting, the coating structure into equiaxed and columnar crystal, and there is little porosity between the coating and the coating. The coating and the matrix have a intergranular combination, and the combination of coating and substrate is changed from mechanical to metallurgical bonding. The material of coating has a transformation, and the $\gamma-\mathrm{Al}_{2} \mathrm{O}_{3}$ and $\beta-\mathrm{Al}_{2} \mathrm{O}_{3}$ are all converted to $\alpha-\mathrm{Al}_{2} \mathrm{O}_{3}$, and $\mathrm{Al}-\mathrm{Ti}$ compound is also generated.

(2) Compared with the plasma coating, the hardness of the laser remelting layer is obviously improved. The hardness curve of laser remelting coating can be divided into three gradients, which are mainly high hardness, decreased hardness and low hardness zone.

(3) The bonding strength of the coating and substrate after laser remelting treatment is far greater than that of the adhesive, but also far greater than that of the plasma sprayed coating.

(4) Hardness and bonding strength are the two most important factors affecting the wear resistance. After a substantial improvement in the hardness and strength of the bond, the wear resistance of the coating has been greatly improved.

\section{Acknowledgements}

The authors would like to be grateful to the Key Program of National Natural Science Foundation of China (Grant No. 51135006).

\section{References}

[1] Xu Binshi, Zhu Shaohua et al. Surface engineering technology in theory. Beijing: National Defence Industry Press,2002,2.

[2] Wang Xinhong, Zou Zengda, Qu Shiyao. Solidification of molten surface strengthening technology - thermal spraying and surfacing technology. Beijing: Chemical Industry Press,2005,5.

[3] Zhang J X, He J G, Dong YC et al, Journal of Materials Processing Technology [J], 2008,197(1 3):31.

[4] Gell M, Jordan E H, Sohn YH et al, Surface and coatings Technology[J], 2001(146 147):48.

[5] Lima R S, Kucuk A, Berndt C C. Materials Science and Engineering A[J], 2001, 313(1 2):75. 
[6] GADOW R, KERN F, KILLINGER A. Manufacturing technologies for nanocomposite ceramic structural materials and coatings [J]. Materials Science and Engineering B , 2008, 148(1-3): 58-64. 